\title{
Transition to College for Students with Autism Spectrum Disorder: Needs and Facilitation Strategies. Is Virtual Reality a Useful Tool in the Transition Process?
}

\author{
Jorge Fernández Herrero ${ }^{1}$ and Gonzalo Lorenzo Lledó ${ }^{2, *}$ \\ ${ }^{1}$ Department of General and Specific Didactics, University of Alicante, Spain \\ ${ }^{2}$ Department of Development Psychology and Teaching, University of Alicante, Spain
}

\begin{abstract}
The number of Autism Spectrum Disorder (ASD) postsecondary students going to University is increasing. Nonetheless, these students face more difficulties than their neuro-typical peers, due to their communication and behaviour impairments. This fact is widely recognized worldwide, and there is an increasing concern in providing them with adequate support both in their transition and beyond. The purpose of this paper is twofold. Firstly, to provide an overall summary of the general requirements of ASD students in the postsecondary education transition with strategies for facilitation, and, secondly, to analyse the possibilities of Virtual Reality (VR) as a support instrument in the transition process. We rely on a brief review of the literature to summarize the main needs and current strategies. In spite of the increasing concern, there is room for establishing general protocols to help the transition process. The use VR in fulfilling this task appears limited, but it seems to be promising.
\end{abstract}

Keywords: ASD, Autism, University, College, Virtual Reality.

\section{INTRODUCTION}

According to the fifth edition of the Statistical Manual of Mental Disorders (DSM-5), Autism Spectrum Disorder (ASD) is characterized by communication and social interaction impairments, as well as behavioural patterns, and restricted and repetitive activities and interests [1]. The number of students with ASD ending their secondary education and going to college or to the job market is increasing worldwide [2], in spite of the exclusion history of disabled people [3]. The reason is threefold: First, the increasing prevalence of ASD [4], second, early detection and treatment effectiveness, that helps students to follow up to secondary education, and third, the increasing social and political awareness on the rights of these students to access and follow a successful career [5].

Equality of Opportunities for ASD students has worldwide recognition. For example, in 1994 the UNESCO World Conference on Special Needs Education, proposed a framework stated in the "Salamanca Statement on Special Education: Access and Quality" [6]. In 1996, the European Parliament passed the "Charter for Persons with Autism" [7] whereby these persons have the right to an accessible and appropriate education. The Convention of the Rights of Persons with Disabilities [8], establishes that the Estates should guarantee the right to education to

Address correspondence to this article at the Department of Development Psychology and Teaching, Faculty of education, University of Alicante Calle Aeroplano, s/n 03690 San Vicente del Raspeig, Alicante, Spain;

Tel: +34 965903400 ext. 2904; E-mail: glledo@ua.es any disabled person at any level, by providing inclusive education and the adequate support. The different countries followed this mandate with different laws and protocols.

However, in spite of the legislative effort and the social concern, we are still far from properly solving the problem of providing a smooth postsecondary education transition for ASD students. Different protocols and support strategies both in the transition to college, as well as during the university period have been used worldwide [9-11]. Also, some experiences have been reported on facilitating ASD youngsters in daily life [12], but they are mostly pilot examples and in general there is no further validation.

In the last few years there has been an increase in research on the use of technology as a tool to enhance ASD students' abilities in different settings. In particular, the use of Virtual Reality (VR) has received special attention, due to the capability of VR to recreate a sense of the real environment. In VR individuals can experience feelings and learn to adapt to difficult situations in a repetitive and unencumbered way. It allows access to characteristics that are particularly well-perceived and accepted by children with ASD [13]. The research on the use of technology in general, and of VR in particular, at the University level, however, is scarce, and the results are partial and non-conclusive.

Therefore, this paper aims to provide an overall summary of the general requirements of ASD students in the postsecondary education transition and seeks to 
uncover whether these requirements are fulfilled. It also aims to analyse the possibilities of a particular technology, namely $V R$, as an instrument in the facilitation of students' needs both in the transition to University or to the job market.

Firstly, we carried out a brief review of the literature: Section 2 details the basis of the review; Section 3 presents a summary of the students' requirements, the most common facilitating strategies before college and later on, as well as the possibilities of VR in helping in these tasks. Section 4 present the discussion of the results. Section 5, with a summary of conclusions, closes the paper.

\section{METHOD}

\subsection{Literature Review}

A review of the research literature was carried out, using as a main databases Web of Science, ERIC, Scopus, and JSTOR. We limited the search to those papers written in English. As main search terms, we used: ASD, Autism, Asperger, University, College and Virtual Reality. As the search formulae we consider the following Boolean operators: 'ASD + University, or ASD + College, or Autism + University, or Asperger + University, or Asperger + College, or ASD + University $+V R$, or ASD + College +VR, Autism + University +VR, or Autism + college + VR, or Asperger + University $+\mathrm{VR}$, or Asperger + College +VR'. This search produced an initial sample of 110 papers published between 1972 and 2018.

\subsection{Literature Analysis}

The aforementioned papers were individually analysed. Then, in dealing with the post-secondary transition, we selected a final sample of 30 papers, published between 2008 and 2018, from which 21 from 2014 onwards, devoted specifically to the transition and adaptation of ASD students to university from secondary education, and some 13 papers dealing with VR for young adults. We classified the papers according to whether they were devoted to the transition in general or to the use of VR for high functioning or Asperger youngsters.

\subsection{Summary of the Problems, Solutions and the Possible Use of VR}

After reviewing the literature, we classified the problems, recommendations and helping strategies and whether VR can be a useful tool. As a way of summarizing the main findings in a synthetic and easyto-follow way, we consider three different items: a) the transition phase; b) at University; c) possibilities of applying VR.

\section{RESULTS}

Out of the literature analysis, a distinction between three main subjects is built: First, most relevant considerations are gathered involving the transition of ASD students to postsecondary Education; Secondly, challenges and strategies for these students once they get to College are listed; And third, suggestions to use VR resources to aid ASD university students are made.

\subsection{Transition to Postsecondary Education: Students' Needs and Facilitating Strategies}

The European Project Autism\&Uni (2013-2016), exhaustively analysed the transition to College, providing an excellent update of the literature, focusing on the difficulties, proposals and solutions so far [14]. As it is stated there, almost all interventions refer to small groups, with no follow-up in the majority of the cases, and therefore, it is difficult to evaluate their benefits.

A general review of experiences and supports up to 2013 appear in Gelbar, Smith, \& Reichow [9] where 20 papers describing small sample experiences both in the transition and at college are described. In Barnhill [11] a general review of the most common supports is given.

Problems' perception are different depending upon who is stating them, either students themselves, parents or teachers [5, 15-17]. Nonetheless, there is a certain consensus a) on the difficulties faced by students with ASD in their access to university or the job market, b) on some efficient ways to deal with those difficulties.

Students with ASD in their transition to university face some important challenges: a) adaptation to a new environment (new centre, sometimes a change of residence and being outside the family; b) academic (academic abilities, proper selection of a subject, a different way of working); c) social (making new friends, stigma, new relationships); d) emotional (stress and anxiety, fear about adaptation and failure).

Focusing on adaptation to the new environment, ASD students do not cope well with changes, and in some cases, starting University means a major 
difference with their comfortable environment (family, friends, and secondary school staff) [18].

As for the academic difficulties, ASD students attending special schools may have some deficits, since normally the focus is put on improving social abilities [3]; it is normally agreed than ASD students are better in STEM subjects (sciences, technology, engineering and medicine), as they are normally more successful in those subjects [19] but there are also ASD students interested in other subjects, and they should not be ignored; finally, for these students to be involved in joint work is more problematic than for their neuro typical peers [16].

In dealing with the social difficulties, the change of environment also involves the possibility of facing stigma, bullying, and communication impairment [20].

Finally, as for emotional challenges, ASD students suffer from stress and anxiety three times more than non-autistic students, in particular under the pressure of change [21], as ASD students have sometimes better grades than their peers as school, may feel the "genius pressure" [22], and thus the fear of failure.

Looking at the facilitation strategies of this step, we have a) academic support (help in choosing a subject, curricula adaptation, mentoring by peers, individual support, special use of computers, exams adaptation); b) environment and day-life support (specific help in navigating day-life problems, summer schools devoted to special training, prior visits to campus, and help in contacting with university special services).

The relationship between secondary school and university are crucial in the success of these facilitating strategies, as well as providing students with knowledge on any help they may apply for once on campus. For instance, prior visits to campus and training summer schools (quite popular in USA and in the UK) help students to adapt [23]. An interesting experience is that of the program STEPS, that is developed in two phases, first at high school and then at the postsecondary stage [24]. A significant problem at this stage is that in order to have access to special university services, students have to disclose their condition, and many of them are reluctant to do so [25]. Help from the intersection between university, parents and secondary school staff may alleviate this problem [26].

\subsection{At University: Challenges and Strategies}

Once the students are at University, and even when there were transition supports, still there are some specific difficulties they may face. Something very important is acceptance and awareness from the different players at university (students, lecturers, and staff) of ASD students and their needs [27-29]. Again, we classify the difficulties into adaptation to the environment problems, academic problems, social problems and emotional problems.

\section{Adaptation to the Environment}

Although previous training and contact with the university environment facilitate adaptation, still ASD students may face difficulties at the University [14]. Information about University services may not be easily available, and deeply relies on students' disclosure. Furthermore, students have to learn in situ how to adapt to daily-life situations.

\section{Academic Problems}

It could be difficult for ASD students to properly follow lectures and cope with academic work. Also to learn how to work in a team, as they tend to be isolated.

\section{Social Problems}

Life at the university requires meeting a significant amount of different people: other students, teachers, supporters, administrative staff, and so on. In many cases they are not aware of the differences and needs of ASD students, making communication and social adaptation a difficult task [30].

\section{Emotional Problems}

Adaptation difficulties may add to anxiety and stress at university, even though ASD students often do not display signs of anxiety, up to reaching the point of psychological crisis [31], enhancing the possibilities of drop-out.

In dealing with facilitation strategies with this step, we have again a) academic support (help in choosing a subject, curricula adaptation, mentoring by peers, individual support, special use of computers, exams adaptation); b) environment and day-life support (specific help in navigating daily problems, informal support networks, setting of a specific office for these students, facilitating students the access to these services).

We should stress that the facilitating strategies vary substantially between countries and universities. They are better stablished in the UK and the USA, but in many European countries budget cuts have affected the support of universities can offer [9]. 


\section{Academic Support}

Setting a specific office to deal with disabled students in general and ASD students in particular, is needed. Providing those students with a tutor who may help in the relationship with lecturers, aiming to provide previews of the lectures, additional time after classes, special use of computers, exam adaptation. In some cases, they also provide a mentoring support, from peers and general volunteers.

\section{Environment and Daily-Life Support}

Mentors and tutors in many occasions also help with environment and daily life support. In some cases universities offer counselling and therapy through specific programs [9, 32].

As for the effectiveness of the facilitation strategies, even though there is no general consensus [33], it is widely recognized that mentoring by peers is highly effective [10, 34-36]. They are also well accepted by ASD students [37]. Mentoring affects positively the integration of ASD students, since it also enhances peers' awareness [38]. In some studies, effectivity is measured via focus groups [39].

It is also commonly agreed that Universities face ASD students as "a problem", so that they have to adapt to the general situation, rather than the obligation of the institution or the education system on creating a more inclusive setting, just to comply with students' rights. This should be challenged.

\subsection{Virtual Reality (VR) and ASD Postsecondary Students}

In the recent treatment of the ASD population, technology is playing an increasing role. Nonetheless, the majority of studies are limited and in general, pilot studies involving children with a small number of participants. Furthermore, there is no clear evidence on whether these interventions are effective, in particular in the long run [40-42].

Amongst the different technological interventions, in recent years VR became quite popular, due to its exante possibilities as a technology suitable to teach ASD students. Early on, it was clear that it may help to isolate the individual, and then enhance his/her concentration on a particular task [43-46]. VR environments are essentially visual and auditory, capacities in which ASD individuals have special strength $[47,48]$. VR technology can easily be adapted to the characteristics of autistic interventions, as situations and social interactions can be carefully designed and controlled in a safe environment [13, 49, 50], and they are particularly useful in high-functioning autism [51].

There are two main types of VR technologies, immersive, and non-immersive. Non-immersive VR is computer assisted and uses simulations, while immersive VR deals with the idea that the user has the feeling of being immersed in the virtual world [52]. In the immersive VR, we can distinguish two main types of technologies, either the creation of Virtual Rooms or the use of Head Mounted Displays (HMD). In Virtual Rooms, the user is surrounded by the virtual world, as it happens in CAVE, [53], or in the Blue Room [54]. HMD have become more popular recently, due to the availability of light devices and their interaction with smartphones [55].

As it happens with other interventions, the large majority of studies so far are pilot studies, dealing with children, with not enough scientific support about its long run efficacy [51].

However, VR technology seems to be specially suited to deal with adaptation to the environment problems for the transition of ASD students to university, since it allows emulation of the environment prior to their transfer to college, and can be used in a repetitive and safe way. For instance, it allows individuals to navigate throughout a university campus [56-58]. Also can be useful for the use of transportation [59-63], social sites, viewing cafeterias and students clubs $[50,64,65]$, as well as to offer training to help adapt to the environment and dynamics in the classrooms [66].

As for academic problems, VR can also be useful, as it allows students to virtually attend lectures [67,68]. Social challenges can also be facilitated by using VR techniques devoted to improve social and communication abilities [67, 69-71]. VR can also be useful to help in mentoring programmes $[72,73]$.

As for emotional problems, VR can also be effective $[56,74,75]$. VR is also potentially useful in working the access to the job market $[12,76,77]$.

Even though there are still very few experiences at this level, the use of VR seems to be very promising, in particular immersive VR with the use of avatars [51]. There is, nevertheless, a word of caution for this technology to be useful: avatars should be veridical and convincing, and able to evoke impressions and 
reactions that are comparable to those evoked by real human beings. So, despite there being a lack of generalized evidence, and as technology is quickly evolving, we only can hope for increasing research in this area, both from the technology improvements as well as the use of this new technology in helping ASD students in their transition after the secondary education.

\section{DISCUSSION}

The increasing demand of special attention to ASD students in their transition to University or the job market is recognized worldwide, as well as the right of those students to meet their demands, and the social interest of helping them in following a professional career [5]. There are different actors involved in properly attending these students. On the one hand, secondary schools, tutors and therapists aimed at facilitating the transition process, and on the other hand, Universities as institutions to deal with those students, once they are enrolled. There is a need for collaboration between both institutions in order to better deal with ASD students' problems. Even though there are some interesting initiatives, as for instance, summer schools prior to starting the academic year, there is in general a lack of awareness of the need of working together in this task.

Universities in general have some offices to attend handicapped students in general, and, in some cases, ASD students. One of the problems for ASD students is that in order to have access to the facilities provided, they have to disclose their condition, and in many cases, they are reluctant to do so [25]. This is one of the points in which collaboration between secondary schools and Universities may facilitate access.

Among the different facilitating strategies, mentoring and tutoring revealed as quite effective in all areas of conflict [10, 34]. In particular mentoring by peers seems to be very well accepted and helpful [38].

The awareness of the different players at university (students, lecturers, and staff) of the existence, rights and needs of ASD students is far from being achieved $[27,28]$. Training is required at all levels in order to comply with ASD students' needs and peculiarities [78]. As it is the case in previous education levels, inclusive education is not only better, but it is a right that has to be facilitated by the institution. It is not the student that has to adapt to the institution, but the other way around [79].
In order to prepare the institution to fulfil its duties in this respect, it is of utmost importance the access and implementation of good practices among all people involved at the university level be attained [80]. An interesting example of this is found in guides of practice developed by Autism\&Uni, where there are specifications for university managers and senior academics, lectures and tutors, and for professionals both in Higher Education and outside [14].

ASD students need support at different levels [17] Before leaving the secondary school, they may learn to adapt to a new environment, to navigate the campus, to learn to live outside their comfort zone, and be independent in daily life requirements; furthermore, they should be conscious of their difficulties, and of the facilities provided by the university, and have access to them. They must be prepared to accept those facilities and adopt their role as university students, overcoming stress and anxiety. Once on campus, they should be able to disclose their condition, register properly and be ready to take advantage of any collaboration they may be provided with, at the social, academic and emotional level [22].

Apart from all facilitating strategies, it is also useful to provide students with accessible help they can use to become familiar with the environment and the challenges ahead. In this respect, Autism\&Uni also developed a toolkit for students to use in their own time to help them and answer some of the questions they may have. Universities in Europe have free access to this toolkit, to use and adapt it to their own needs [14].

Some technologies can be useful in helping ASD students in their transition problems to University. Even though there is still scarce evidence, it seems that the use of Virtual Reality has a great potential as a facilitating strategy [77]. The fact that virtual environments can re-create real ones, and the student can train social, emotional, and academic situations in a safe way, suggests that VR can be an appropriate tool to help these students [64].

Nonetheless, in order for VR to be useful, a great amount of research is called for. For this to be effective, multidisciplinary teams should work together in order a) to produce technological improvements in order to create environments easy to deal with and as close to reality as possible; b) to create avatars that permit the emulation of real-life situations in a credible way; c) to design situations that mimic those real-life situations the students are likely to face; d) to control 
those situations and interact with the students in a way that they could train and learn; e) to test the prototypes and control for their effectivity; f) to validate the results in a scientific way [42].
This is a tremendous challenge indeed, and due to the diversity and differences among ASD students, it may require a long process. However, if this helps both

Table 1: Facilitating Strategies at and in the Transition to University

\begin{tabular}{|c|c|c|c|}
\hline Sensible areas & Difficulties & Strategies & Is VR useful? \\
\hline \multirow{5}{*}{$\begin{array}{l}\text { Environment } \\
\text { adaptation }\end{array}$} & New environment & Navigating the facilities & Yes \\
\hline & Change of residence & Vocational help & Yes \\
\hline & New dynamics & Experimenting the dynamics at the classroom & Yes \\
\hline & Sensorial over-exposition & Accomodation search & \\
\hline & & Sensorial adaptation & Yes \\
\hline \multirow{2}{*}{ Mentoring } & Supervision and formation & Selection of mentors & Yes \\
\hline & & Training and supervision of mentors & Yes \\
\hline \multirow{6}{*}{ Curricular adaptation } & & Flexibility in the selection of subjects & \\
\hline & Helping Resources & Alternatives to the difficulties of team work & \\
\hline & Adaptation via technologies & Flexibility in duration of exams & \\
\hline & & Helping flexibility & Yes \\
\hline & & Adapted Information & \\
\hline & New peers & $\begin{array}{l}\text { Visual signalling and technological environments } \\
\text { to facilitate learning and evaluation. }\end{array}$ & Yes \\
\hline \multirow{4}{*}{ Socialization } & Fear to rejection and stigma & Relationship with peers & Yes \\
\hline & Fear to life in campus outside home & Participation in social activities & Yes \\
\hline & Social isolation and reject & Help to integrate in dorms & Yes \\
\hline & & $\begin{array}{l}\text { Awareness, information, visibility and } \\
\text { normalization of ASD problems }\end{array}$ & Yes \\
\hline \multirow{4}{*}{ Job facilitation } & Scarcity of supply & Active search of labour supply & \\
\hline & Lack of awareness & Preparation of CV & Yes \\
\hline & Lack of specific job market integration plans & Preparation of interviews & Yes \\
\hline & & Institutional support & \\
\hline \multirow{3}{*}{ Emotional support } & $\begin{array}{l}\text { Problems to understand others' emotions } \\
\text { Difficulty to express owns' emotions }\end{array}$ & Access to therapy & Yes \\
\hline & $\begin{array}{c}\text { Anxiety, depression, frustration, hyper activity, } \\
\text { temper }\end{array}$ & Supporting social interactions & Yes \\
\hline & Own's situation awareness & Motivational support from teachers/lecturers & Yes \\
\hline \multirow{3}{*}{$\begin{array}{l}\text { Adaptive training of } \\
\text { the staff }\end{array}$} & Lack of specific training & Understanding the needs of the ASD students & \\
\hline & Lack of resources & Learning strategies & Yes \\
\hline & Lack of motivation & Individual support & \\
\hline \multirow{3}{*}{ Institutional Problems } & $\begin{array}{l}\text { Lack of acknowledgment of ASD students' } \\
\text { rights }\end{array}$ & Legislation & \\
\hline & Lack of legislation and specific protocols & & \\
\hline & Differences in the perception of the needs & Protocols & \\
\hline
\end{tabular}


the ASD population and institutions to properly get an inclusive university education it is worth a try.

\section{CONCLUSIONS}

- $\quad$ There is a need for collaboration between both secondary schools, tutors and therapists and Universities in order to better deal with ASD students' transition process, adaptation, needs and problems [26].

- This collaboration should focus, among other things, in facilitating access for these students to the facilities and services they need, avoiding to force them to necessary disclose their condition exposing them to stigmatization.

- Among the different facilitating strategies, mentoring, particularly by peers [38], and tutoring revealed as quite effective in all areas of conflict $[10,34]$.

- University must guarantee inclusive education, and to do so all players involved (students, lecturers, and staff) are to be trained at all levels in order to comply with ASD students' needs and peculiarities [78]. An interesting example of this is found in guides of practice developed by Autism\&Uni [14].

- $\quad$ Apart from all facilitating strategies, it is also useful to provide students with accessible help they can use to become familiar with the environment and the challenges ahead. In this respect, Autism\&Uni also developed a free access toolkit for European university students to use and customize in their own time [14].

- Virtual Reality has a great potential as a facilitating strategy [77]. The fact that virtual environments can re-create real ones, and the student can train for social, emotional, and academic situations in a safe way, suggests that VR can be an appropriate tool to help these students [64], although a great deal of research is needed for this to be supported.

\section{REFERENCES}

[1] Association AP. Diagnostic and statistical manual of mental disorders. 5 ed. Arlington, VA: American Psychiatric Publishing 2013.

[2] MacLeod A, Green S. Beyond the books: case study of a collaborative and holistic support model for university students with Asperger's syndrome, Studies in Higher. Education 2009; 34: 631-646. https://doi.org/10.1080/03075070802590643
Reid DK, Knight MG. Disability justifies exclusion of minority studies: A critical history grounded in disability studies. Educ Res 2006; 35: 18-23. https://doi.org/10.3102/0013189X035006018

Wingate M, Kirby RS, Pettygrove S, Cunniff C, Schulz E, Ghosh $\mathrm{T}$, et al. Prevalence of autism spectrum disorder among children aged 8 years-autism and developmental disabilities monitoring network, 11 sites, United States, 2010. MMWR Surveill Summ 2014; 63(2): 1-21.

[5] Camarena P, Sarigiani P. Postsecondary Educational Aspirations of High-Functioning Adolescents With Autism Spectrum Disorders and Their Parents. Focus Autism Dev Disabil 2009; 24(2): 115-128. https://doi.org/10.1177/1088357609332675

[6] U.N.E.S.C.O. The Salamanca Statement and Framework for Action on special needs education. In: Conferencia Mundial sobre Necesidades Educativas Especiales: Acceso y Calidad. Salamanca: UNESCO 1994; pp. 1-49.

[7] Autism Europe. Charter for Persons with Autism [Internet] European Parliament 1996. Available from: http://www.autismeurope.org/blog/1996/12/11/charter-forpersons-with-autism Download, 3/11/2018

[8] UN. Convention on the Rights of Persons with Disabilities [A/RES/61/106] [Internet]. Report No.: [A/RES/61/106]. Available from: https://www.un.org/development/desa/ disabilities/resources/general-assembly/convention-on-therights-of-persons-with-disabilities-ares61106.html Download 3/11/2018

[9] Gelbar N, Smith I, Reichow B. Systematic review of articles describing experience and supports of individuals with autism enrolled in college and university programs. J Autism Dev Disord 2014; 44(10): 2593-601. https://doi.org/10.1007/s10803-014-2135-5

[10] Ames M, McMorris C, Alli L, Bebko J. Overview and Evaluation of a Mentorship Program for University Students With ASD. Focus Autism Dev Disabil 2016; 31(1): 27-36. https://doi.org/10.1177/1088357615583465

[11] Barnhill GP. Supporting students with Asperger's syndrome on college campuses: current practices. Focus Autism Dev Disabil 2016; 31(1): 3-15. https://doi.org/10.1177/1088357614523121

[12] Strickland D, Coles C, Southern L. JobTIPS: A Transition to Employment Program for Individuals with Autism Spectrum Disorders. J Autism Dev Disord 2013; 43(10): 2472-2483. https://doi.org/10.1007/s10803-013-1800-4

[13] Bellani M, Fornasari L, Chittaro L, Brambilla P. Virtual reality in autism: state of the art. Epidemiol Psychiatr Sci 2011; 20(3): 235-238. https://doi.org/10.1017/S2045796011000448

[14] Autism\&Uni. Widening Access to Higher Education. Available from: http://www.autism-uni.org/outputs/Download 20/9/2018

[15] Fleischer A. Support to students with Asperger syndrome in higher education- the perspective of three relatives and three coordinators. Inter J Rehabil Res 2012; 35(1): 54-61. https://doi.org/10.1097/MRR.0b013e32834f4d3b

[16] Van Hees V, Moyson T, Roeyers H. Higher education experiences of students with autism spectrum disorder: challenges, benefits and support needs. J Autism Dev Disord 2015; 45(6): 1673-1688. https://doi.org/10.1007/s10803-014-2324-2

[17] Cai R, Richdale A. Educational Experiences and Needs of Higher Education Students with Autism Spectrum Disorder. J Autism Dev Disord 2016; 46(1): 31-41. https://doi.org/10.1007/s10803-015-2535-1

[18] Van Schalkwyk G, Volkmar F. Autism Spectrum Disorders: Challenges and opportunities for transition to adulthood. Child Adolesc Psychiatr Clin N Am 2017; 26(2): 329-339. https://doi.org/10.1016/j.chc.2016.12.013 
[19] Wei X, Christiano E, Yu J, Blackorby J, Shattuck P, Newman L. Postsecondary Pathways and Persistence for STEM Versus Non-STEM Majors: Among College Students with an Autism. Spectr Disord J Autism Dev Disord 2014; 44(5): 1159-1167. https://doi.org/10.1007/s10803-013-1978-5

[20] Tan L, Hughes C, Foster J. Abilities, Disabilities and Possibilities: A qualitative study exploring the academic and social experiences of gifted and talented students who have co-occurring learning disabilities. J Pedagog Dev 2016; 6(2): $30-42$.

[21] Lawrence D, Alleckson D, Bjorklund $P$. Beyond the roadblocks. Transitioning to adulthood with Asperger's disorder. Arch Psychiatr Nurs 2010; 24: 227-238. https://doi.org/10.1016/i.apnu.2009.07.004

[22] Martin N, Beardon L, Hodge N, Goodley D, Madriaga M. Towards an inclusive environment for university students who have Aspergers' syndrome. J Incl Pract Furth High Educ 2008; 1: 3-14.

[23] Mitchell W, Beresford B. Young people with autism and Asperger's syndrome planning for and anticipating the move to college: what support a positive transition. Br J Spec Educ 2014; 41(2): 151-171.

https://doi.org/10.1111/1467-8578.12064

[24] White S, Elias R, Capriola-Hall N, Smith I, Conner C, Asselin $S$, et al. Development of a college transition and support program for students with Autism Spectrum Disorder. J Autism Dev Disor 2017; 47(10): 3072-3078 https://doi.org/10.1007/s10803-017-3236-8

[25] Davidson J, Henderson V. "Coming out" on the spectrum: autism, identity and disclosure. Soc Cult Geogr 2010; 11: 155-170.

https://doi.org/10.1080/14649360903525240

[26] Pinder-Amaker S. Identifying the unmet needs of college students on the autism spectrum. Harv Rev Psychiatry 2014; 22(2): 125-137. https://doi.org/10.1097/HRP.0000000000000032

[27] Nevill R, White S. College students' openness toward autism spectrum disorders: improving peer acceptance. J Autism Dev Disord 2011; 41(12): 1619-1628. https://doi.org/10.1007/s10803-011-1189-x

[28] Tripton L, Blacher J. Brief Report: Autism awareness: Views from a campus community. J Autism Dev Disord 2014; 44(2): 477-483.

https://doi.org/10.1007/s10803-013-1893-9

[29] Volkmar F, Jackson S, Hart L. Transition issues and challenges for youth with Autism Spectrum Disorders. Pediatr Ann 2017; 46(6): 219-223. https://doi.org/10.3928/19382359-20170519-03

[30] Gardiner E, larocci G. Students with Autism Spectrum Disorder in the University Context: Peer Acceptance Predicts Intention to Volunteer. J Autism Dev Disord 2014; 44(5): 1008-1017. https://doi.org/10.1007/s10803-013-1950-4

[31] Van Berjeijk E, Klin A, Volkmar F. Supporting more able students on the autism spectrum: college and beyond. J Autism Dev Disord 2008; 38(7): 1359-70. https://doi.org/10.1007/s10803-007-0524-8

[32] Pugliese C, White S. Brief report: Problem solving therapy in college students with ASD: Feasibility and preliminary efficacy. J Autism Dev Disord 2014; 44(3): 719-729. https://doi.org/10.1007/s10803-013-1914-8

[33] Rao P, Beidel D, Murray M. Social skills interventions for children with Aspergers' syndrome or High Functioning Autism. A Review and recommendations. J Autism Dev Disord 2008; 38: 353-361. https://doi.org/10.1007/s10803-007-0402-4

[34] Ness B. Supporting self-regulated learning for college students with Aspergers' syndrome: Exploring the "strategies for college learning." Model Mentor Tutoring Partnersh Learn 2013; 21(4): 356-377.

https://doi.org/10.1080/13611267.2013.855865

[35] Tobajas F, De Armas V, Cabello M, Grijalvo F. Supporting students with special needs at university through peer mentoring. In: 2014 IEEE Global Engineering Education Conference (EDUCON). Istanbul, Turkey: IEEE 2014; pp. 701-705.

https://doi.org/10.1109/EDUCON.2014.6826170

[36] Roberts N, Birmingham E. Mentoring University Students with ASD: A Mentee-centered Approach. J Autism Dev Disabil 2017; 47(4): 1038-1050. https://doi.org/10.1007/s10803-016-2997-9

[37] Siew C, Mazzucchelli T, Rooney R, Girdler S. A specialist peer mentoring program for university students on the autism spectrum: A pilot study. PLOS One 2017; 12(7): 1-18. https://doi.org/10.1371/journal.pone.0180854

[38] Matthews N, Ly A, Goldberg W. College Students Perceptions of Peers with Autism Spectrum Disorder. J Autism Dev Disord 2015; 45(1): 90-99. https://doi.org/10.1007/s10803-014-2195-6

[39] Hillier A, Goldstein J, Murphy D, Triestsch R, Keeves J, Mendes $\mathrm{E}$, et al. Supporting university students with autism spectrum disorder. Autism 2018; 22(1): 20-28. https://doi.org/10.1177/1362361317699584

[40] Knight V, McKissick B, Saunders A. A review of technologybased interventions to teach academic skills to students with autism spectrum disorders. J Autism Dev D 2013; 43(1): 2628-48. https://doi.org/10.1007/s10803-013-1814-y

[41] Was S, Porayska-Pomsta K. The uses of cognitive training technologies in the treatment of Autism. Spectr Disord Autism 2014; 18(8): 851-871.

https://doi.org/10.1177/1362361313499827

[42] Grynszpan O, Weiss P, Perez-Diaz F, Gal E. Innovative technology-based interventions for autism spectrum disorders: a meta-analysis. Autism 2014; 18(4): 346-361. https://doi.org/10.1177/1362361313476767

[43] Charitos D, Karadanos E, Triantafillou S, Koukouvinou S, Martakos D. Employing virtual reality for aiding the organisation of autistic children behaviour in everyday tasks. In: Proceedings of the 3rd International Conference on Disability, Virtual Reality and Associated Technologies (ICDVRAT). Alghero, Sardinia 2000; pp. 147-152.

[44] Strickland D, Marcus L, Hogan K, Mesibov G, McAlister D. Using Virtual Reality as a Learning Aid for Autistic Children. In: Proceedings of the Autism France Third International Conference on Computers and Autism. Nice 1995; pp. 119132.

[45] Strickland D. A virtual reality application with autistic children. Presence: Teleoperators and Virtual. Environments 1996; 5(3): 319-329.

https://doi.org/10.1162/pres.1996.5.3.319

[46] Strickland D. Virtual reality for the treatment of autism. In: Riva G, Ed. Amsterdam: IOS Press 1997; pp. 81-86.

[47] Grandin T. Thinking in pictures. New York, NY: Random House 2006.

[48] Grandin T, Panek R. The Autistic Brain: Thinking Across the Spectrum. Boston, MA: Houghton Mifflin Harcourt 2013.

[49] Pantelidis $V$. Suggestions on when to use and when not to use virtual reality in education. VR Sch 1996; 2(1): 18.

[50] Parsons S, Mitchell P, Leonard A. The use and understanding of virtual environments by adolescents with autistic spectrum disorders. J Autism Dev Disord 2004; 34: 449-466. https://doi.org/10.1023/B:JADD.0000037421.98517.8d

[51] Georgescu A, Kuzmanovic B, Roth D, Bente G, Vogeley K. The use of virtual characters to assess and train non-verbal 
communication in high functioning autism. Front Hum Neurosci 2014; 8: 1-17. https://doi.org/10.3389/fnhum.2014.00807

[52] Sherman W, Craig A. Understanding Virtual Reality-Interface, Application and Design. San Francisco, CA: Morgan Kaufmann Publishers Inc 2002.

[53] Cruz-Neira C, Sandin D, DeFanti T, Kenyon R, Hart J. The CAVE: audio visual experience automatic virtual environment. Commun ACM 1992; 35(6): 64-72. https://doi.org/10.1145/129888.129892

[54] Wallace S, Parsons S, Westbury A, White K, Bailey A. Sense of presence and atypical social judgments in immersive virtual reality: Responses of adolescents with Autistic Spectrum Disorders. Autism 2010; 14(3): 199-213. https://doi.org/10.1177/1362361310363283

[55] Ray A, Deb S. Smartphone Based Virtual Reality Systems in Classroom Teaching - A Study on the Effects of Learning Outcome. In: 2016 IEEE Eighth International Conference on Technology for Education (T4E). Mumbai, India: IEEE 2016; pp. 68-71. https://doi.org/10.1109/T4E.2016.022

[56] Volioti C, Tsiatsos T, C. Karagiannidis SM. VLSS - Virtual Learning and Social Stories for Children with Autism,. In: IEEE 14th International Conference on Advanced Learning Technologies. Athens: IEEE 2014; pp. 606-610. https://doi.org/10.1109/ICALT.2014.177

[57] Cheng Y, Huang C-L, Yang C-S. Using a 3D Immersive Virtual Environment System to Enhance Social Understanding and Social Skills for Children With Autism Spectrum Disorders. Focus Autism Dev Disabil 2015; 30(4): 222-236. https://doi.org/10.1177/1088357615583473

[58] Fornasari L, Chittaro L, leronutti L, Cottini L, Dassi S, Cremaschi $\mathrm{S}$, et al. Navigation and exploration of an urban virtual environment by children with autism spectrum disorder compared to children with typical development. Res Autism Spectr Disord 2013; 7(8): 956-965.

https://doi.org/10.1016/j.rasd.2013.04.007

[59] Rutten A, Cobb S, Neale H, Kerr S, Leonard A, Parsons S, et al. The AS interactive project: single-user and collaborative virtual environments for people with high-functioning autistic spectrum disorders. J Vis Comput Animat 2003; 14: 233-241. https://doi.org/10.1002/vis.320

[60] Parsons S, Leonard A, Mitchell P. Virtual environments for social skills training: Comments from two adolescents with autistic spectrum disorder. Comput Educ 2006; 47(2): 186206. https://doi.org/10.1016/i.compedu.2004.10.003

[61] Bian D, Wade JW, Zhang L, Bekele E, Swanson A, Crittendon JA, et al. A Novel Virtual Reality Driving Environment for Autism Intervention. In: Stephanidis C, Antona M, editors. UAHCl'13 Proceedings of the 7th international conference on Universal Access in HumanComputer Interaction: user and context diversity. Vegas, NV: Springer-Verlag Berlin, Heidelberg: Las 2013; pp. 474-483. https://doi.org/10.1007/978-3-642-39191-0 52

[62] Bernardes M, Barros F, Simoes M, Castelo-Branco M. A serious game with virtual reality for travel training with Autism Spectrum Disorder. In: 2015 International Conference on Virtual Rehabilitation (ICVR). Valencia, Spain: IEEE 2015. https://doi.org/10.1109/ICVR.2015.7358609

[63] Cox D, Brown T, Ross V, Moncrief M, Schmitt R, Gaffney G, et al. Can Youth with Autism Spectrum Disorder Use Virtual Reality Driving Simulation Training to Evaluate and Improve Driving Performance? An Exploratory Study. J Autism Dev Disord 2017; 47(8): 2544-2555.

https://doi.org/10.1007/s10803-017-3164-7
[64] Cobb S, Beardon L, Eastgate R, Glover T, Kerr S, Neale H, et al. Applied virtual environments to support learning of social interaction skills in users with Asperger's Syndrome. Digit Creat 2002; 11(22): 11-22.

https://doi.org/10.1076/digc. 13.1.11.3208

[65] Mitchell P, Parsons S, Leonard A. Using virtual environments for teaching social understanding to adolescents with autistic spectrum disorders. J Autism Dev Disord 2007; 37(3): 589600. https://doi.org/10.1007/s10803-006-0189-8

[66] Jarrold W, Mundy P, Gwaltney M, Bailenson J, Hatt N, Mclntyre $\mathrm{N}$, et al. Social Attention in a Virtual Public Speaking Task in Higher Functioning Children. Autism Autism Res 2013; 6(5): 393-410. https://doi.org/10.1002/aur.1302

[67] Schmidt M. Designing for Learning in a Three-Dimensional Virtual Learning Environment: A Design-Based Research Approach. J Spec Educ Technol 2014; 29(4): 59-71. https://doi.org/10.1177/016264341402900405

[68] Stichter J, Laffey J, Galyen K, Herzog M. iSocial: Delivering the Social Competence Intervention for Adolescents (SCI-A) in a 3D Virtual Learning Environment for Youth with High Functioning Autism. J Autism Dev Disord 2014; 44(2): 417430.

https://doi.org/10.1007/s10803-013-1881-0

[69] Cheng Y, Ye J. Exploring the social competence of students with autism spectrum conditions in a collaborative virtual learning environment - the pilot study. Comput Educ 2010; 54(4): 1068-1077. https://doi.org/10.1016/j.compedu.2009.10.011

[70] Kandalaft M, Didehbani N, Krawczyk D, Allen T, Chapman S. Virtual Reality Social Cognition Training for Young Adults with High-Functioning Autism. J Autism Dev Disord 2013; 43(1): 34-44.

https://doi.org/10.1007/s10803-012-1544-6

[71] Ke F, Lee $S$. Virtual reality based collaborative design by children with high-functioning autism: design-based flexibility, identity, and norm construction. Interact Learn Environ 2016; 24(7): 1511-1533.

https://doi.org/10.1080/10494820.2015.1040421

[72] Trepagnier C, Olsen D, Boteler L, Bell C. Virtual Conversation Partner for Adults with Autism. Cyberpsychology Behav Soc Netw 2011; 1(2): 21-27. https://doi.org/10.1089/cyber.2009.0255

[73] Herring $P$, Kear K, Sheehy K, Jones R. A virtual tutor for children with autism. J Enabling Technol 2017; 11(1): 19-27. https://doi.org/10.1108/JET-01-2016-0006

[74] Austin D, Abbott J-A, Carbis C. The use of virtual reality hypnosis with two cases of autism spectrum disorder: a feasibility study. Contemp Hypn 2008; 25(2): 102-109. https://doi.org/10.1002/ch.349

[75] Ringland K, Wolf C, Dombrowski L, Hayes G. Making "Safe": Community-Centered Practices in a Virtual World Dedicated to Children with Autism. CSCW '15. In: Proceedings of the 18th ACM Conference on Computer Supported Cooperative Work \& Social Computing. Vancouver, BC, Canada: ACM New York 2015; pp. 1788-1800. https://doi.org/10.1145/2675133.2675216

[76] Smith MJ, Ginger EJ, Wright K, Wright MA, Taylor JL, Humm LB, et al. Virtual Reality Job Interview Training in Adults with Autism Spectrum Disorder. J Autism Dev Disord 2014; 44(10): 2450-2463

https://doi.org/10.1007/s10803-014-2113-y

[77] Bozgeyikli L, Bozgeyikli E, Raij A, Alqasemi R, Katkoori S, Dubey R. Vocational Rehabilitation of Individuals with Autism Spectrum Disorder with Virtual Reality. ACM Trans Access Comput TACCESS 2017; 10(2): 1-25. https://doi.org/10.1145/3046786 
[78] Gobbo K, Schmulsky S. Faculty experience with college students with Autism Spectrum Disorders: A qualitative study of challenges and solutions. Focus Autism Disab 2014; 29: 13-22.

https://doi.org/10.1177/1088357613504989

[79] Hemings B, Kemmis S, Reupert A. Practice architectures of university inclusive education teaching in Australia. Prof Dev Educ 2013; 39(4): 470-478.

https://doi.org/10.1080/19415257.2013.796293
[80] Zager D, Alpern C. College-based inclusion programming for transition-age students with autism. Focus Autism Dev Disab 2010; 25: 151-157.

https://doi.org/10.1177/1088357610371331

DOI: https://doi.org/10.6000/2292-2598.2019.07.02.2 